Charina Melinda C. Elgar-Reyes, MD

Patrick Joseph A. Pardo, MD

'Department of Otorhinolaryngology

Philippine General Hospital

University of the Philippines Manila
Correspondence: Charina Melinda C. Elgar-Reyes, MD Department of Otorhinolaryngology

Ward 10, Philippine General Hospital

Taft Avenue, Ermita, Manila 1000

Philippines

Phone: (632) 5264360

Fax: (632) 5255444

Email:chow_md@yahoo.com

Reprints will not be available from the author.

\section{Relapsing Polychondritis}

Relapsing Polychondritis is an auto-immune disease that can present with a variety of non-specific symptoms involving the ears, nose, throat, head and neck. Although uncommon, we should be aware of this disease entity and should include it as a differential diagnosis in patients who complain of difficulty breathing. It is also prudent that we never forget to look at the larger picture beyond specific symptoms to understand and explain a patient's condition.

\section{CASE}

An 18-year-old female was admitted at the pediatric emergency room (PER) due to recurrent, non-productive cough associated with occasional difficulty of breathing. One year prior to this admission, the patient complained of on and off cough with no other associated symptoms. There was no improvement with antibiotics she was given at a local clinic and the cough spontaneously resolved only to recur. Along with the recurrent cough, she eventually experienced difficulty of breathing and found herself in and out of the hospital, treated for bronchial asthma or pulmonary tuberculosis. Due to the symptoms' recurring and worsening nature, the family consulted at our institution, where she was referred to the ORL service for further evaluation. On examination, she exhibited hoarseness, occasional stridor and difficulty of breathing. She also had a characteristic saddle nose deformity. Flexible nasolaryngotracheoscopy revealed a smooth extraluminal bulge extending from the area of the subglottis up to the second tracheal ring, at the 4 to 7 o'clock position of the neck. A neck soft tissue lateral (STL) film showed widening of the prevertebral soft tissue spaces with irregular calcifications at the level of C4 to C6 pushing the trachea anteriorly, causing narrowing of the tracheal air column (Figure 1). CT scans revealed a homogenous, ill-defined mass, posterolateral to the trachea, pushing the trachea anteriorly (Figure 2).

A CT-guided aspiration biopsy (CT-GAB) was deferred by the radiologist who opined that the biopsy would be technically difficult since the mass was small and adjacent to the vessels. Prophylactic tracheostomy and open biopsy were recommended but no consent was given by the family and they opted to go home.

Four months after, the patient returned to the PER with difficulty of breathing. She was also noted to have bilateral auricular perichondritis and ocular redness 


\section{FEATURED GRAND ROUNDS}

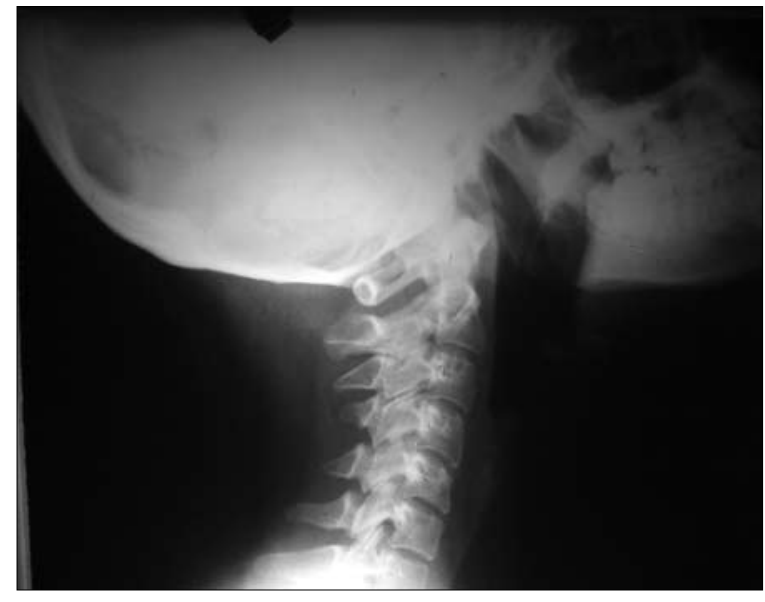

Figure 1. Neck soft tissue lateral (STL) film showing widening of prevertebral soft tissue spaces with irregular calcifications at the $\mathrm{C} 4$ to $\mathrm{C} 6$ level.

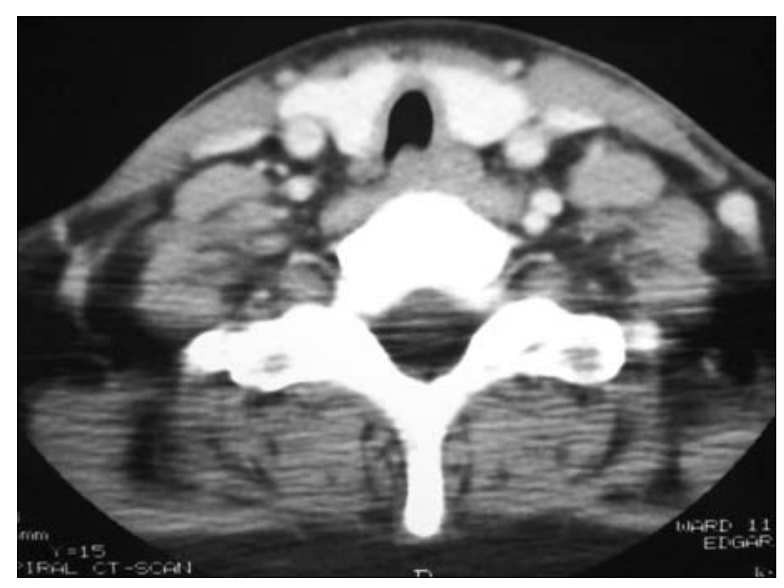

Figure 2. CT scan showed homogenous, ill-defined mass, posterolateral to the trachea.

which were described by the mother as usually associated with her episodes of dyspnea. An emergent tracheostomy and suspension laryngoscopy were performed, revealing marked enlargement of the cricoid and arytenoid cartilages. Both appeared to be heavily calcified. The thyroid cartilage was thinned out and was laterally splayed. On tracheoscopy, a smooth, mucosal swelling and smooth tracheal rings with concentric narrowing were seen. An open biopsy revealed an extraluminal hard, gritty mass adherent to the thyroid cartilage, posteriorly extending from the thyroid notch to the first tracheal ring. Biopsy specimens measuring approximately $1.5 \mathrm{x}$ $1.5 \mathrm{~cm}$ aggregate diameter were sent for histopathology which revealed fragments of mature hyaline cartilage and lamellar bone with fragments of fibrocartilaginous tissue of chronic non-specific inflammation.

With the history of recurrent cough and dyspnea, saddle-nose deformity, binaural perichondritis, ocular redness/inflammation and histologic finding of cartilage inflammation, an assessment of relapsing polychondritis was made. She was referred to the rheumatology service for further evaluation and started on steroids with note of improvement of her symptoms.

\section{DISCUSSION}

Relapsing polychondritis is a rare, auto-immune condition. It is characterized by recurrent inflammation leading to destruction of cartilage and other connective tissues. The ear, nose and tracheobronchial cartilage are most commonly affected. ${ }^{1}$ Males and females are affected equally with an average age at diagnosis of 51 years old. Only a few cases of relapsing polychondritis have been reported in children. ${ }^{2}$

It is believed that auto-antibodies to cartilage components specifically to collagen type II cause inflammatory infiltration and cellular mechanisms involving lysosomal enzyme release and eventually result in the destruction of the cartilage due to the following mechanisms: excessive release of proteolytic enzymes by chondrocytes, down-regulation of collagen synthesis and autoimmune reactions against cartilage intercellular matrix components. ${ }^{3}$ Histopathologic studies reveal cartilage destruction with loss of basophilic staining and islands of lymphocytic infiltration. Subsequently, fragmentation of cartilage occurs with replacement by fibrous tissue. ${ }^{4}$

Relapsing polychondritis most often manifests as swelling and erythema of the ear (88\%) and arthralgias (81\%). Repeated auricular inflammation, scarring and retraction may cause the appearance of "cauliflower ears." Ocular inflammation manifests in almost $60 \%$ of patients., Relapsing polychondritis may also result in dermatologic, cardiac, renal and neurologic manifestations.

Respiratory involvement is the most common cause of death. ${ }^{6}$ Chondritis may affect the external nares, nasal septal turbinates, eustachian tubes, epiglottis, larynx, thyroid, cricoid, arytenoid, trachea and bronchi. Nasal chondritis involves the distal part of the nasal septum and may lead to a saddle nose deformity. Laryngotracheal involvement may initially manifest as recurrent cough. Hoarseness, dyspnea, anterior neck pain, stridor and wheezing may also be observed. The obstruction is due to 
edema, vocal cord palsy and fixed subglottic or bronchial stenoses. This may suddenly exacerbate to dynamic airway collapse necessitating the need for tracheostomy. ${ }^{1,5}$ Lifethreatening respiratory involvement is more common in females with a 2.6:1 ratio. $^{4}$

Due to the wide-spectrum of signs and symptoms and their non-specificity, a diagnosis of relapsing polychondritis is often only attained a few years after the first manifestation of the disease and after repeated consults with various specialists. The time from onset of initial symptoms to diagnosis varies from 8 months to 13 years. ${ }^{4} \quad$ McAdam, et al, ${ }^{7}$ proposed diagnostic criteria based on the most common clinical features of relapsing polychondritis. This was further modified by Damiani and Levine $^{8}$ (See Table 1):

Table 1. Clinical diagnostic criteria for relapsing polychondritis: ${ }^{6}$

\begin{tabular}{|c|c|}
\hline & Clinical features \\
\hline McAdam, et. al. ${ }^{7}$ & $\begin{array}{l}\text { The presence of three or more of the following criteria: } \\
\text { - Recurrent chondritis of both auricles }\end{array}$ \\
\hline Damiani and Levine ${ }^{8}$ & $\begin{array}{l}\text { - Nonerosive inflammatory polyarthritis } \\
\text { - Chondritis of nasal cartilages } \\
\text { - Ocular inflammation (conjunctivitis, keratitis, scleritis/episcleritis and/or } \\
\text { uveitis) } \\
\text { - Chondritis of the respiratory tract involving laryngeal and/or tracheal cartilage } \\
\text { - Audiovestibular damage (neurosensory hearing loss, tinnitus, and/or vertigo) }\end{array}$ \\
\hline & $\begin{array}{l}\text { The presence of one of the following criteria: } \\
\text { - Three or more of McAdam's signs (histological confirmation is not necessary) } \\
\text { - One or more of McAdam's signs with positive histological confirmation by } \\
\text { biopsy of the cartilage } \\
\text { - Involvement of two or more separate anatomical locations with response to } \\
\text { steroids and/or dapsone }\end{array}$ \\
\hline
\end{tabular}

Our patient presented with five of McAdam's signs namely: recurrent chondritis of both ears, chondritis of nasal cartilages, chondritis of the laryngotracheal cartilage and ocular inflammation. Hence, a diagnosis of relapsing polychondritis was established. There is no specific laboratory exam for relapsing polychondritis. However, normocytic, normochromic anemia, mild leukocytosis, thrombocytosis, hypergammaglobulinemia and elevated ESR are often observed. ${ }^{6,9}$ Our patient manifested with normocytic, hypochromic anemia, mild leukocytosis and with thrombocytosis.

Bronchoscopy is an indispensable tool in establishing the exact site, nature and severity of airway involvement. It may show an inflammation of the tracheobronchial tree with narrowing or collapse of the airways. Bronchoscopy must be done with caution as it may cause dyspnea, airway collapse, hypoxia, asphyxia and death. ${ }^{4}$ Bronchoscopy in this patient revealed an inflamed and edematous epiglottis with progressive concentric narrowing of the tracheal space. A computed tomography (CT) scan can show deformity or circumferential thickening of the cricoid or tracheal cartilage, edema and fibrosis or ossification of the soft tissues. ${ }^{6}$

The course of relapsing polychondritis may vary from immediate death to a relatively benign and painless course for several years. The prognosis is based on the degree of respiratory and cardiovascular involvement. ${ }^{2}$

Corticosteroids are the mainstay of treatment in relapsing polychondritis. This is due to their antiinflammatory and anti-chondrolytic properties. Nonsteroidal anti-inflammatory drugs, dapsone and colchicines may be used for mild cases. Immunosuppressive therapy in the form of cyclophosphamide, azathioprine and cyclosporine is used for severe cases. ${ }^{2,5}$ Our patient was initially treated with hydrocortisone $100 \mathrm{mg}$ IV every 12 hours and was later shifted to prednisone $40 \mathrm{mg}$ per day. Her disease was sufficiently controlled with this medication.

Tracheostomy, as was performed in our patient, may be necessary when there is respiratory distress and subglottic involvement. Other possible adjuncts to medical therapy include continuous positive airway pressure for symptomatic relief, and metallic stent placement. ${ }^{5,10}$

\footnotetext{
REFERENCES

1. Prakash UBS. Uncommon causes of cough ACCP evidence-based clinical practice guidelines. Chest 2006; 129(1).

2. Soto-Romero I, Fustes-Morales AJ, De Leon-Bojorge B, Contreras-Ruiz J, RuizMaldonado R. Relapsing Polychondritis: a pediatric case. Pediatr Dermatol 2002 19(1): 60-63.

3. Sacco O, Fregonese B. Severe endobronchial obstruction in a girl with relapsing polychondritis: treatment with Nd YAG laser and endobronchial silicon stent. Eur Respir J 1997; 10: 494-496.

4. Sarodia BD, Dasgupta A and Mehta AC. Management of airway manifestations of relapsing polychondritis: case reports and review of literature. Chest 1999;116;16691675.

5. Kent PD, Michet CJ and Luthra HS. Relapsing polychondritis, Curr Opin Rheumatol 2004; 16(1):56-51

6. Alatas F, Ozkan R, Metintas M, Moral H, Erginel S, Ucgun I. Relapsing polychondritis. Respirology 2003; 8:99-103

7. McAdam LP, O'Hanlan MA, Bluestone R and Pearson CM. Relapsing polychondritis. Prospective study of 23 patients and a review of the literature. Medicine 1976; 55:193215.

8. Damiani JM and Levine HL. Relapsing polychondritis. Laryngoscope 1979; 89: 929 46.

9. Peebo BB, Peebo M and Frennesson C. Relapsing polychondritis: a rare disease with varying symptoms. Acta Ophthalmol Scand 2004; 82: 472-475

10.Lee CC and Singer AJ. Respiratory failure due to subglottic stenosis from relapsing polychondritis.
} 